\title{
THE EFFECT OF IMMUNOSUPPRESSION ON VASCULARISED ALLOGRAFTS
}

\author{
A PRELIMINARY REPORT
}

\author{
K. DOI, G. De SANTIS, D. I. SINGER, J. V. HURLEY, B. McC O'BRIEN, S. M. McKAY, \\ M. J. HICKEY, B. F. MURPHY
}

From St Vincent's Hospital, Melbourne

Five vascularised allografts of the knee joint were performed in dogs immunosuppressed with cyclosporin $A$ and azathioprine. Three survived with normal function for 3 to 4 months after operation. One of the unsuccessful grafts had a failed vascular anastomosis, the other an inadequate blood level of cyclosporin $A$. All three successful grafts healed well. In two, bone scans, radiographs and biopsies were indistinguishable from successful autografts; in the third the blood supply to the graft failed despite patent anastomoses but the graft healed well with good function.

All three grafts were rejected within 2 to 3 weeks of withdrawal of cyclosporin A and azathioprine. In non-immunosuppressed dogs, allografts of the knee, both vascularised and non-vascularised, were rejected within a few days of operation. In two non-vascularised allografts, administration of cyclosporin and azathioprine had no apparent effect on the rate of rejection of the graft.

The most frequent site of a primary malignant tumour of bone is the lower end of the femur. Surgical excision of the tumour with an adequate margin of uninvolved tissue commonly requires removal of the lower end of the femur, and destruction of the knee. The knee may also be destroyed by severe trauma. Attempts to replace a lost knee joint have had limited success. Artificial joints are

K. Doi, MD, Assistant Professor

Department of Orthopaedic Surgery, Yamaguchi University School of Medicine, 1141 Kogushi, Ube-Shi, Yamaguchi-Ken 755, Japan.

G. De Santis, MD, Specialist in Orthopaedics

Assistente della Clinica Ortopedica e Traumatologica dell' Universita de Modena, Modena 41100, Italy.

D. I. Singer, MD, Hand Associate

Hand Rehabilitation Center, 901 Walnut Street, Philadelphia, PA 19107, USA

J. V. Hurley, MD, PhD, FRCPA, FRCPath, FRACP, FRACR, Professor and Consultant Pathologist

B. McC O'Brien, $C M G$, BSc, MD, MS, FRCS, FRACS, FACS, FRCS Ed(Hon) Director, Microsurgery Research Centre

S. M. McKay, Cert Appl Sci, Cert Am An Tech, Technician, Experimental Medical and Surgical Research Unit

M. J. Hickey, BSc (Hons), Research Assistant, Microsurgery Research Centre

B. F. Murphy, FRACP, Assistant Renal Physician

St Vincent's Hospital, Victoria Parade, Fitzroy 3065, Victoria, Australia.

Correspondence should be sent to Mr B. McC O'Brien.

(C) 1989 British Editorial Society of Bone and Joint Surgery

$0301-620 X / 89 / 4128 \$ 2.00$

J Bone Joint Surg [Br] 1989;71-B :576-82. rarely able to tolerate the stresses placed on them by active young people, and there is a high incidence of fracture of the prosthesis, aseptic loosening and infection (Burrows, Wilson and Scales 1975; Sim and Chao 1979). Arthrodesis will restore stability at the expense of movement, but may be technically difficult if large amounts of bone have been resected.

The ideal replacement for a lost joint is a graft similar to the tissue that has been lost. Non-vascularised grafts of joints have been studied for almost 80 years. Autografts have in general survived: allografts have been almost uniformly unsuccessful. In small animals successful revascularisation of autografts has been achieved, but in larger animals degeneration of the articular cartilage develops some months after grafting and impairs function. This degeneration appears to be due to lack of subchondral support during the period of revascularisation of the graft (Brown and Cruess 1982).

Allografts fail because of immune rejection. Bone is strongly antigenic but cartilage is only weakly so and may even be immunoprivileged (Heyner 1973; Elves 1976; Gertzbein and Lance 1976; Brown and Cruess 1982). Freezing has been used to reduce the antigenicity of the graft, but deep frozen osteochondral allografts have had only limited success clinically and show a high incidence of serious complications (Parrish 1973; Mankin et al 1976; Mankin, Doppelt and Tomford 1983; Mnaymneh et al 1985; Urbaniak and Black 1985). 
In recent years techniques have been developed which permit the transfer of vascularised grafts of joints. Vascularised autografts have been transferred to both men and animals with long term survival and normal articular cartilage (Judet and Padovani 1968; Goldberg, Porter and Lance 1980; Daniller and O'Brien 1983; Morrison O'Brien and MacLeod 1984; O'Brien and Morrison 1987). However, the clinical use of this type of graft is limited to the transfer of toe joints to the hand, and of joints taken from amputated parts.

For large joints vascularised allografts offer a possible alternative. However, in animals, despite the use of a variety of drugs to suppress the immune response, vascularised allografts have almost always been rejected within a few days. In the last few years use of a new drug, cyclosporin A, has produced a dramatic improvement in the results of allografting a variety of organs. Published evidence suggests that cyclosporin A may also allow the survival of large osteochondral allografts; two groups have claimed long term survival of limb transfers in rats (Hewitt et al 1983; Kim et al 1984). A recent paper describes the transfer of either a whole hand or a composite multi-tissue flap in baboons immunosuppressed with cyclosporin $A$ and prednisolone; of 11 grafts, the survival of five was said to be excellent and a further three survived after a reversible episode of rejection (Daniel et al 1986). Studies of renal allotransplantation in dogs indicate that a combination of cyclosporin $\mathrm{A}$ and azathioprine is more effective than either drug alone (Homan et al 1980, 1981; Aeder et al 1983).

We now report the successful survival for several months of vascularised allografts of the knee joint in dogs immunosuppressed with high dose cyclosporin and azathioprine. The grafts healed in a similar manner to vascularised autografts. Joint function and the histological appearance of bone and cartilage were normal throughout the period of immunosuppression.

\section{MATERIALS AND METHODS}

We used outbred dogs and five types of graft. Except for the vascularised autografts, each graft required the use of two dogs - a donor and a recipient.

Group 1. Vascularised autografts (6).

Group 2. Vascularised allografts without immunosuppression (3).

Group 3. Vascularised allografts immunosuppressed with cyclosporin and azathioprine (5).

Group 4. Non-vascularised allografts without immunosuppression (3).

Group 5. Non-vascularised allografts immunosuppressed with cyclosporin and azathioprine (2).

\section{Surgical technique}

Removal of graft. In the donor dog an extraperiosteal dissection is made of the distal femur and proximal tibia.
Major muscles are cut at their tendinous origin or insertion, the femur divided $5.5 \mathrm{~cm}$ proximal and the tibia $5.0 \mathrm{~cm}$ distal to the knee and the graft isolated on a pedicle of the femoral artery and vein.

Insertion of graft. In the recipient dog the knee joint is removed by a dissection similar to that described above. The donor graft is inserted and fixed with 6-hole dynamic compression plates. Tendons are repaired with nonabsorbable sutures. The donor femoral artery is anastomosed end-to-side to the femoral artery of the recipient dog, and the donor femoral vein anastomosed end-to-end to the proximal end of the divided recipient femoral vein, whose distal end is ligated. A vacuum drain is inserted and left in place for two days; the limb is enclosed in a plaster spica for three weeks.

In the non-vascularised grafts (Groups 4 and 5) the femoral vessels are not included in the graft removed from the donor dog.

\section{Immunosuppression (Groups 3 and 5)}

Cyclosporin A. Daily oral administration of $20 \mathrm{mg} / \mathrm{kg} / \mathrm{day}$ starting immediately after the operation.

Azathioprine. $1.0 \mathrm{mg} / \mathrm{kg} /$ day orally starting on the morning of the operation.

\section{Assessment of results}

A bone scan was performed with Technetium phosphate 1 to 3 days, 3 weeks, 6 weeks and 3 months after operation, and 2 to 3 weeks after cessation of immunosuppression.

Arteriography was performed three months after operation, immediately before cessation of immunosuppression, and at sacrifice.

Bone and cartilage biopsy. Tetracycline, $25 \mathrm{mg} / \mathrm{kg}$, was given intramuscularly daily for three days, starting one month after operation, and a similar course was repeated each month thereafter until sacrifice in order to label newly-formed bone in and around the graft. Biopsies were taken of the junctions of recipient bone and graft, and of cartilage and subarticular bone of the graft, three months after operation and at sacrifice. Part of each biopsy was embedded in LR white resin, and sawn and ground sections of undecalcified bone were prepared and examined for tetracycline fluorescence under UV illumination. The remainder of each biopsy was decalcified, embedded in paraffin and used to prepare histological sections by standard techniques.

Radiographs were taken of the area of each graft at operation and at monthly intervals.

Biochemical and haematological estimations of blood cyclosporin A level, WBC, haemoglobin, blood urea, blood creatinine and liver function tests were made twice weekly for two months after operation and then weekly.

Clinical assessment was made by periodic testing of weight-bearing ability, active and passive movement at the knee, ligament stability and appearance of graft. At the time of biopsy, macroscopic assessment was made of the state of articular cartilage, ligaments and the internal appearance of the joint. 


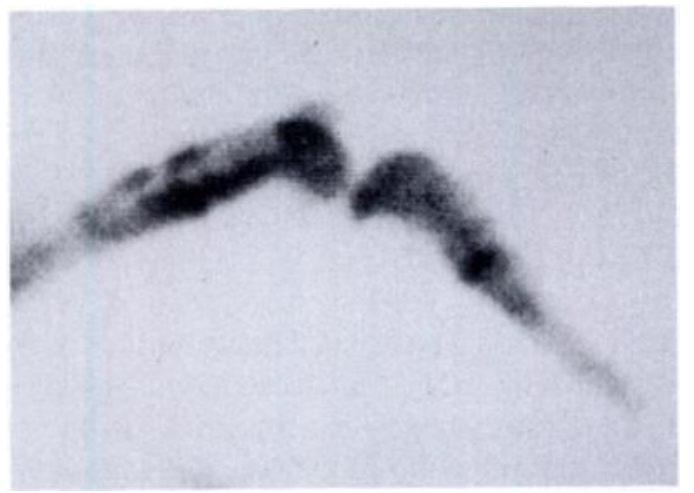

Fig. 1

Bone scan of successful, immunosuppressed allograft two months after grafting, showing uniform uptake of tracer in both femoral and tibial elements of the graft.

\section{RESULTS}

Group 1 - Vascularised autografts. Six autografts were inserted. In the first two dogs there was early failure of the vascular anastomoses. The remaining four grafts were successful, with similar findings in each:

Bone scans showed uniform and rapid uptake of tracer at all postoperative stages indicative of active circulation within the graft.

Radiology. Four weeks after operation, callus was visible arising from both donor and recipient bone and at eight weeks the fracture lines, though still visible, were bridged by callus. At 12 weeks firm bony union was present at each end of the graft. At no stage was any abnormality apparent in the joint space.

Arteriograms made at sacrifice showed a patent vascular anastomosis and a normal distribution of blood vessels within the graft.

Histology. At sacrifice the articular surfaces of the knee were normal macroscopically, and articular cartilage, menisci and ligaments were intact. Histological examination revealed no abnormality of either bone or articular cartilage. Tetracycline labelling showed discrete bands of fluorescence, indicative of active bone formation, in fracture callus and both graft and recipient bone.

Clinical. Two months after operation, animals used their operated knee almost normally and were fully weightbearing. At three months, before they were killed, animals walked normally but limped slightly when running. The knee was strong with a range of active and passive movement similar to that of the unoperated knee. The thigh muscles showed considerable atrophy at the level of the operation.

Group 2 - Vascularised allografts without immunosuppression. Three grafts were inserted.

Clinical. Redness and swelling were apparent around the grafted knee within 24 hours of operation. The inflammatory signs increased progressively until the animals were killed 10 days after grafting. In two of the three dogs, the wound disrupted and discharged pus.

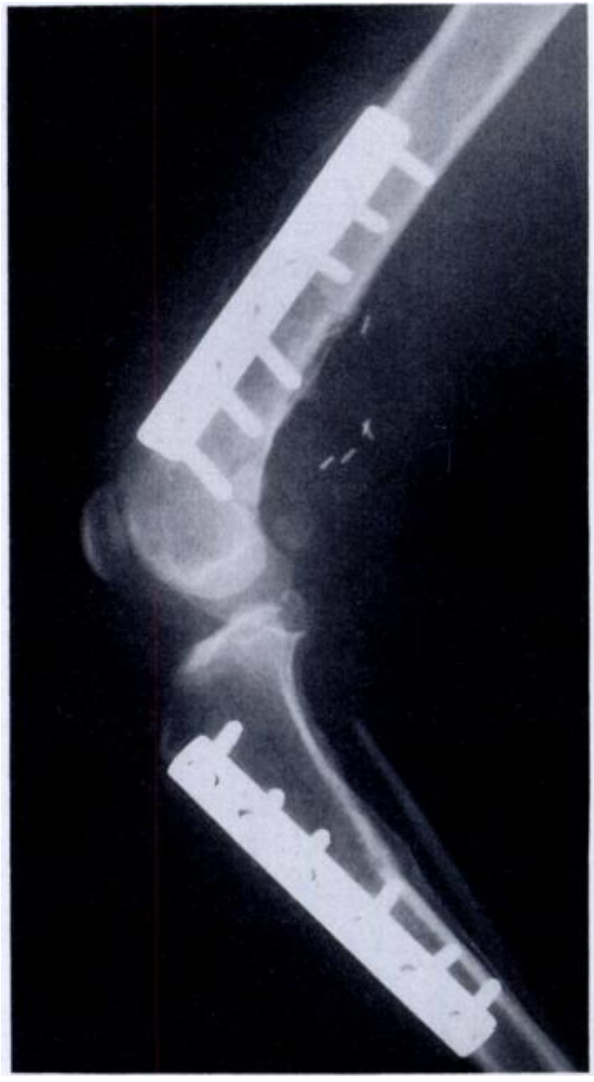

Fig. 2

Radiograph of successful, immunosuppressed allograft, 12 weeks after grafting. Mature bony union is present at each end of the graft.

Bone scans. Two days after operation each dog showed 'cold' spots in a 'hot' scan, a pattern similar to that seen in the kidney during renal transplant rejection. Five days after grafting no uptake of tracer could be detected within the graft.

Macroscopic examination. Dogs were killed five days after the first completely 'cold' scan was obtained. In two dogs the anastomosis of the femoral artery was patent, but the femoral vein had thrombosed. The main popliteal artery in these animals was patent but its branches were thrombosed. In the third dog both femoral artery and vein were thrombosed.

Radiology. No callus was visible in radiographs taken at the time of sacrifice, 5 to 7 days after operation.

Histology. No histological studies were made of these grafts, but the WBC had increased to 38 to $40000 / \mathrm{mm}^{3}$ by five days after operation (normal range 4 to 11000 / $\mathrm{mm}^{3}$ ).

Group 3 - Vascularised allografts immunosuppressed with azathioprine and cyclosporin A. Five grafts of this type were performed. In one animal, a bone scan two days after operation indicated that the vascular anastomosis had failed and when this was confirmed at operation on the third day the animal was killed. A second graft (87/ 18 ), whose bone scan had a patchy appearance two days 


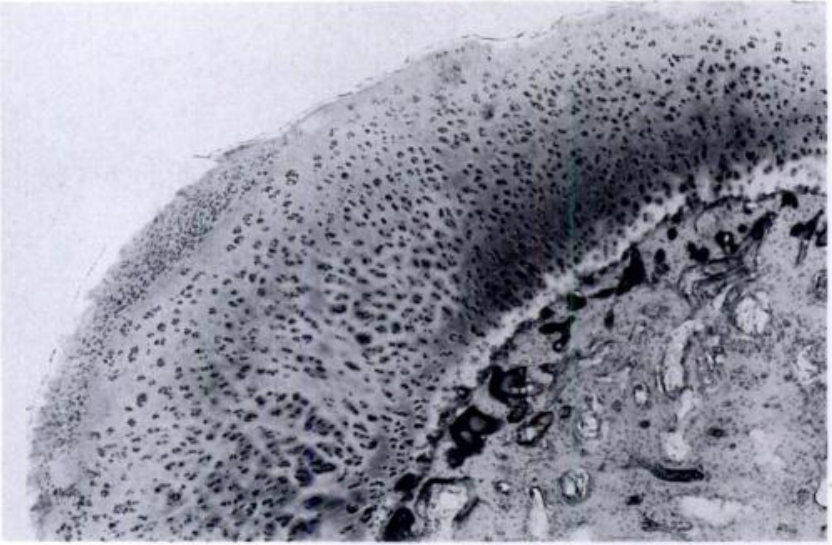

Fig. 3

Biopsy of successful, immunosuppressed allograft, three months after grafting. Articular cartilage and subarticular bone are alive and of normal appearance. (Resin embedded section, haematoxylin and eosin. $\times 32$ ).

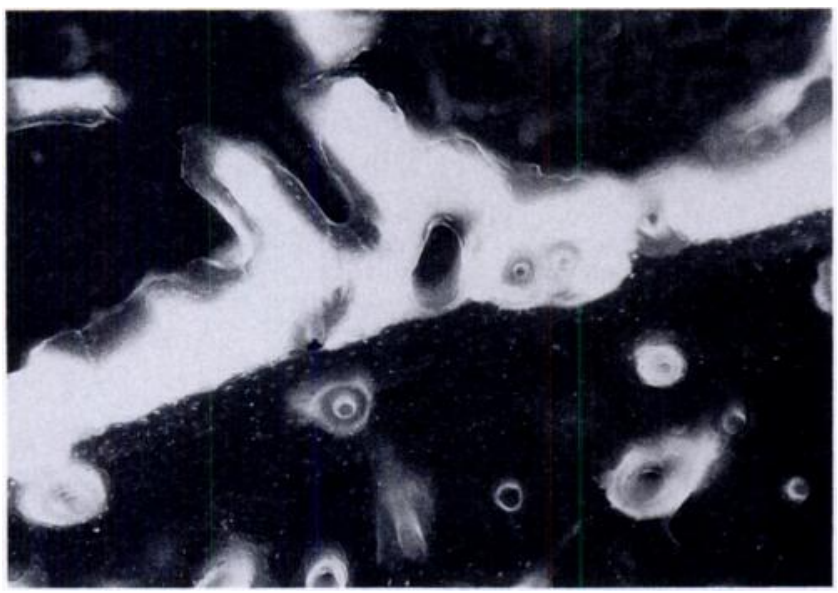

Fig. 4

Biopsy of successful, immunosuppressed allograft, three months after grafting. Tetracycline has been incorporated diffusely into callus (above) and in concentric rings around the Haversian canals of the cortical bone of the graft (below). (Unstained resin embedded section viewed under ultraviolet light, $\times 50$ ).

after operation but a patent anastomosis on radioisotopic angiography, developed signs of rejection within a few days of operation and the dog was killed. The only determination of the blood level of cyclosporin in this animal was at 24 hours after operation. The level was only $86 \mathrm{ng} / \mathrm{ml}$ - far below the anticipated level of at least $200 \mathrm{ng} / \mathrm{ml}$.

The remaining three grafts of this type were successful. The dogs remained well without significant change in body weight throughout the three or four months of immunosuppression except for temporary gastrointestinal problems in one animal.

Clinical. The gait, weight-bearing ability and range of active and passive movement were as in successful autografts; animals could walk and run normally apart from the effects of atrophy of the thigh muscles. No evidence of infection or inflammation was seen.
Special investigations. Although all three successful grafts showed similar clinical features, the findings in the other modes of examination - bone scan, angiography, radiography and histology - were quite different in two animals, $86 / 150$ and $87 / 11$ from those in the third dog, 87/20.

In all types of examination in dogs $86 / 150$ and $86 /$ 11 , the results were substantially identical with those seen in successful vascularised autografts. Bone scans at all stages showed active, uniform uptake (Fig. 1). Radiology revealed active formation of callus from either side of the fracture lines with firm bony union by three months (Fig. 2), and angiograms at three months showed patent anastomoses and normal vasculature within the grait.

At a biopsy operation three months after grafting, the articular surfaces of the knee looked macroscopically normal and there was free bleeding from the edges of the wound. The biopsy specimen showed no histological abnormality of either bone or articular cartilage (Fig. 3). Prominent bands of tetracycline labelling indicated that active formation of new bone had taken place in donor and recipient bone and in fracture callus during the three months (Fig. 4).

In the third clinically successful graft, $87 / 20$, a bone scan two days after operation showed only patchy uptake of tracer and large 'cold' areas within the graft. A radioisotopic angiogram showed that the arterial anastomosis was patent. Ten days after operation a bone scan showed no uptake within the graft and angiography at three months showed obstruction of the artery supplying the graft. Radiographs showed no callus formation on the donor side of the proximal junction and at three months this showed the appearances of non-union. By contrast the distal junction had united firmly by bone at three months. A biopsy at this time showed the articular cartilage on the inner aspect of the knee to appear normal macroscopically but there was no bleeding from the edges of the biopsy wound. Histology showed that all bone cells had disappeared: all lacunae in the graft were empty. Most of the articular cartilage was acellular but occasional scattered groups of apparently viable chondrocytes were visible. The ground substance of the cartilage was normal in amount but stained abnormally, appearing pink rather than blue in haematoxylin and eosin preparations. Tetracycline labelling was visible in recipient bone and callus but not in the bone of the graft.

When administration of azathioprine and cyclosporin A was stopped (after three months in dogs $87 / 11$ and $87 / 20$ and four months in $\operatorname{dog} 86 / 150$ ), the clinical appearance remained unaltered for approximately two weeks. The knees then swelled and obvious signs of rejection rapidly developed. In one dog the wound broke down.

Bone scans two weeks after withdrawal of azathioprine and cyclosporin A showed no uptake in any of the three grafts. All three animals were killed three weeks after cessation of immunosuppression. The articular 
cartilage and joint lining in dogs $86 / 150$ and $87 / 11$ showed no macroscopic abnormality, but the cartilage in dog $87 /$ 20 appeared thinner than usual and had a roughened and irregular surface. Histological examination of the two previously viable grafts, $86 / 150$ and $87 / 11$, showed that all bone cells within the graft had died and disappeared and that only scattered groups of cartilage cells remained alive (Fig. 5). Small blood vessels within the graft were necrotic but no inflammatory cells were visible adjacent to them. Sections across the vascular pedicle showed a femoral artery of normal appearance and a femoral vein occluded by partially organised thrombus. There was a dense mononuclear cell infiltration in the wall of the vein, with necrosis of the muscle and elastic tissue.

Blood cyclosporin level. The blood cyclosporin A levels associated with the three successful grafts and the graft that was rejected within a few days of operation $(87 / 18)$ are shown in Table I. It can be seen that the levels of cyclosporin $A$ in dogs $86 / 150$ and $87 / 11$ lay within the therapeutic range throughout the whole period of drug administration. By contrast, the level in dog $87 / 20$, in which it seemed that blood supply to the graft failed soon after operation, was either below or at the lower limit of the therapeutic range in the first two weeks after operation, but subsequently was maintained at a satisfactory level. The only reading available in $\operatorname{dog} 87 / 18$, which rejected within two weeks, was well below the therapeutic range.

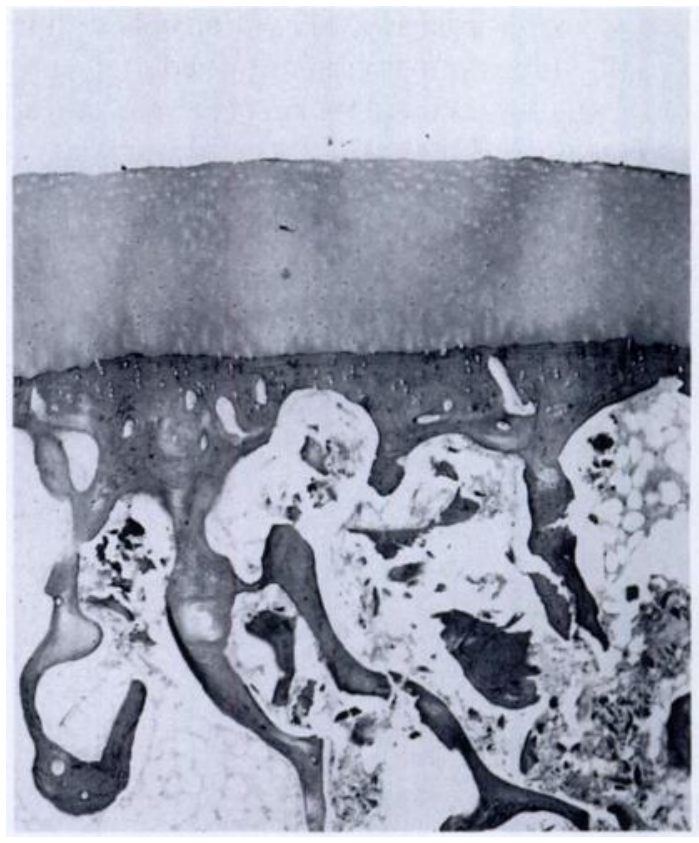

Fig. 5

Biopsy of successful, immunosuppressed allograft, one month after withdrawal of immunosuppression. Noliving cells are present in subchondral bone and only scattered living cells are seen in the lacunae of the articular cartilage (Haematoxylin and eosin $\times 40$ ).

Table I. Blood level of cyclosporin $\mathrm{A}$ in $\mathrm{ng} / \mathrm{ml}$ in dogs with vascularised allografts at intervals after operation

\begin{tabular}{|c|c|c|c|c|}
\hline \multirow{2}{*}{$\begin{array}{l}\text { Time after } \\
\text { operation }\end{array}$} & \multicolumn{4}{|c|}{ Dog number } \\
\hline & $86 / 150$ & $87 / 11$ & $87 / 18$ & $87 / 20$ \\
\hline Pre-operative & 0 & 0 & 0 & 0 \\
\hline I day & $404^{*}$ & & 86 & 80 \\
\hline I week & 226 & 290 & & 190 \\
\hline 2 weeks & 354 & 1498 & & 170 \\
\hline 3 weeks & 460 & 2193 & & 655 \\
\hline 4 weeks & 332 & 1315 & & 1107 \\
\hline 5 weeks & 1250 & 810 & & 568 \\
\hline 6 weeks & 1983 & 1900 & & 343 \\
\hline 7 weeks & 962 & 2500 & & 508 \\
\hline 8 weeks & 1000 & 1895 & . & - \\
\hline 10 weeks & 530 & 1387 & & 527 \\
\hline 12 weeks & 1200 & 1323 & & 736 \\
\hline 14 weeks & 697 & $437+$ & & \\
\hline 16 weeks & 763 & $16+$ & & \\
\hline 18 weeks & $77+$ & & & \\
\hline
\end{tabular}

* therapeutic range 150 to $500 \mathrm{ng} / \mathrm{ml}$

+ after withdrawal of cyclosporin $A$ and azathioprine 
Group 4 - Non-vascularised allografts without immunosuppression. Three grafts were performed.

Clinical. Redness and swelling became apparent around each graft within three days of operation. The inflammation increased progressively until the animals were killed 8,14 and 15 days after grafting.

A bone scan two days after operation showed no uptake of isotope in the graft in one dog.

Macroscopic examination of the knees at sacrifice showed obvious necrosis of both bone and cartilage. No histological studies were performed.

Group 5 - Non-vascularised allografts immunosuppressed with cyclosporin $A$ and azathioprine. Two grafts were performed.

Clinical. The progress of the grafts was similar to those in group 4. Redness and swelling were prominent around the knee three days after operation, inflammation progressed rapidly and the dogs were killed 14 and 15 days after operation.

Blood cyclosporin estimations, in both cases the level lay within or above the therapeutic range throughout the interval between operation and sacrifice.

The macroscopic findings at sacrifice were indistinguishable from those in group 4 . No histological studies were made.

\section{DISCUSSION}

The findings in group 1 confirm previous reports that a vascularised transplant of the knee joint can be performed by microsurgical techniques without undue difficulty (Judet and Padovani 1968; Goldberg et al 1980). In such autografts both bone and cartilage cells remain alive and function normally and the joint retains normal structure and function.

Vascularised allografts are however rejected within a few days, and comparison between the findings in groups 2 and 4 indicates that vascularisation of a graft has little effect on the rate of graft rejection. Rejection of a vascularised graft appears to begin in relation to small blood vessels within the graft rather than the large vessels of the vascular pedicle. In group 2, the bone scan studies showed patchy impairment of uptake 48 hours after operation and by five days all blood flow within the graft had ceased. However the femoral artery was clearly patent on the angiograph at five days, and in some animals was still patent at sacrifice.

The results obtained in group 3 show that cyclosporin A supplemented by azathioprine is a much more effective way of preventing rejection of a large osteochondral graft than any other type of immunosuppression so far reported. Three of the five vascularised allografts protected in this way survived with normal function throughout 3 to 4 months of immunosuppression. Avoidable technical factors were the cause of failure of the two unsuccessful grafts in this group. In one animal the vascular anastomosis was unsatisfactory: in the other the blood level of cyclosporin was very low, one day after operation, because the dog vomited the drug soon after it had been administered. The bone scan in this animal was patchy on the second postoperative day and the graft was rejected within a few days. To avoid repetition of this problem it is proposed in future experiments to administer $10 \mathrm{mg} / \mathrm{kg}$ cyclosporin intravenously on the morning of operation and repeat the dose 24 hours later.

Of the three clinically successful vascularised allografts, the findings in two dogs were indistinguishable from those in successful vascularised autografts. Bone scans showed normal circulation within the graft; bone formation continued normally within the graft and within three months the grafts had healed by bony union. A biopsy at three months showed normal bone and cartilage cells and no histological abnormality of the critically important articular cartilage.

The third clinically successful allograft showed very different findings. In this animal bone scans and angiography indicated that the blood supply to the graft failed within a few days of operation. This failure may have been related to the unusually low level of cyclosporin in the animal during the first two weeks after operation. Despite the failure of its blood supply the graft showed no clinical signs of rejection, and it can be regarded as equivalent to a successful, non-vascularised allograft. However, biopsy at three months after operation revealed that both bone and cartilage cells within the graft had died, and had the animal survived this would almost certainly have led to impaired function of the grafted joint. The findings in group 5 suggest that the behaviour of this graft was unusual and that the combination of cyclosporin and azathioprine is unable to prevent rapid rejection of most non-vascularised allografts.

All three clinically successful allografts were rejected within 2 to 3 weeks of stopping the immunosuppression. This is in accord with clinical experience that indefinite administration of cyclosporin is necessary for survival of renal, cardiac and hepatic grafts. However it cannot be assumed that this will necessarily be the case for vascularised osteochondral grafts. Renal glomeruli and cardiac muscle fibres are permanent structures devoid of regenerative ability, and the turnover of both renal tubular cells and hepatocytes is extremely slow. By contrast bone exhibits a regular turnover of its constituent cells. It has been estimated that total replacement of cells in a major bone requires several years (Sissons 1979), but only a few months are needed to repopulate the lost cells within a large bone infarct (Catto 1977). Furthermore, the several types of cell within bone have different origins. Osteoblasts normally arise by division of cells of the same type, but there is evidence that in some circumstances bone marrow cells or cells in circulating blood may give rise to osteoblasts (Brown and Cruess 1982). Osteoclasts are derived from circulating cells of the mononuclear phagocyte system. Endothelial cells can divide in situ, but new blood vessels can also arise in 
adjacent tissues and grow into the graft. It may well be that during 6 to 12 months of immunosuppression, replacement of donor bone cells by host cells and ingrowth of small host blood vessels will be sufficient to allow survival of the graft without further drug administration. We plan further experiments to examine this possibility.

It is encouraging that the dogs in the present study showed so few toxic symptoms. This suggests that if a long period of immunosuppression is necessary it is unlikely to be accompanied by serious side effects.

No previous study of the transfer of vascularised allografts of a major joint under this type of immunosuppression has been published, but two recent reports demonstrate the ability of cyclosporin to delay rejection of osteochondral grafts. Weiland and his colleagues (Paskert et al 1987) showed that this drug could delay rejection of a vascularised allograft of the knee in inbred rats, and a Swiss group, studying the healing of vascularised autografts and allografts of bone in dogs, claimed that a four-week course of cyclosporin improved allograft survival (Aebi et al 1986). They suggested that a longer course of cyclosporin A might lead to even better results. Our study supports this suggestion and shows that vascularised allografts of bone and cartilage will not only survive but heal in place just as well as vascularised autografts, as long as immune rejection is suppressed by administration of a combination of azathioprine and cyclosporin A.

No benefits in any form have been received or will be received from a commercial party related directly or indirectly to the subject of this article.

\section{REFERENCES}

Aebi M, Regazzoni P, Perren SM, Harder F. Microsurgically revascularised bone allografts with immunosuppression with cyclosporin: preliminary report of the effect in an animal model CSC. Transplantation 1986;42:564-8.

Aeder MI, Sutherland DER, Lewis WI, Najarian JS. Combination immunotherapy with low-dose cyclosporine and azathioprine in splenectomized canine recipients of renal allografts. Transplant Proc 1983:15: No. 4 Suppl. 1:2933-8.

Brown KLB, Cruess RL. Bone and cartilage transplantation in orthopaedic surgery: a review. J Bone Joint Surg [Am] 1982;64A :270-9.

Burrows HJ, Wilson JN, Scales JT. Excision of tumours of humerus and femur, with restoration by internal prostheses. $J$ Bone Joint Surg [ Br] 1975:57-B:148-59.

Catto M. Ischaemia of bone. J Clin Path 1977; Suppl 11 :78-93.
Daniel RK, Egerszegi EP, Samulack DD, et al. Tissue transplants in primates for upper extremity reconstruction: a preliminary report. $J$ Hand Surg [Am] 1986;11A :1-8.

Daniller A, O'Brien BMcC. Toe-to-hand microsurgical transfers: report of the subcommittee on neurovascular island transplants. $J$ Hand Surg [ Am] 1983;8:738-40.

Elves SW. Newer knowledge of the immunology of bone and cartilage. Clin Orthop 1976;120:232-59.

Gertzbein SD, Lance EM. The stimulation of lymphocytes by chondrocytes in mixed cultures. Clin Exp Immunol 1976;24:102-9.

Goldberg VM, Porter BB, Lance EM. Transplantation of the canine knee joint on a vascular pedicle: a preliminary study. $J$ Bone Joint Surg [ Am] 1980;62-A :414-24.

Hewitt CW, Black KS, Fraser LA, et al. Cyclosporin-A (CyA) is superior to prior donor-specific blood (DSB) transfusion for the extensive prolongation of rat limb allograft survival. Transplant Proc 1983:15:514-7.

Heyner S. The antigenicity of cartilage grafts. Surg Gynaecol Obstet 1973;136:298-305.

Homan WP, French ME, Fabre JW, et al. The interaction of cyclosporin A with other immunosuppressive agents in dog recipients of renal allografts. Transplant Proc 1980:12:287-90.

Homan WP, French ME, Millard PR, Morris PJ. A study of eleven drug regimens using cyclosporin-A to suppress renal allograft rejection in the dog. Transplant Proc 1981:13:397-401.

Judet H, Padovani JP. Transplantation d'articulation complète avec rétablissement circulatoire immédiat par anastomoses artérielles et veineuses. Mem Acad Chir (Paris) 1968:94:520-6.

Kim SK, Aziz S, Oyer P, Hentz VR. Use of cyclosporin A in allotransplantation of rat limbs. Ann Plast Surg 1984:12:249-55.

Mankin HJ, Fogelson FS, Thrasher AZ, Jaffer F. Massive resection and allograft transplantation in the treatment of malignant bone tumors. N Engl J Med 1976;294:1247-55.

Mankin HJ, Doppelt S, Tomford W. Clinical experience with allograft implantation: the first ten years. Clin Orthop 1983;174:69-86.

Mnaymneh W, Malinin TI, Makley JT, Dick HM. Massive osteoarticular allografts in the reconstruction of extremities following resection of tumors not requiring chemotherapy and radiation. Clin Orthop 1985;197:76-87.

Morrison WA, O'Brien BMcC, MacLeod AM. Ring finger transfer in reconstruction of transmetarcarpal amputations. J Hand Surg $1984 ; 9 A: 4-11$.

O'Brien BMcC, Morrison WA, eds. Reconstructive microsurgery Edinburgh, etc: Churchill Livingstone, 1987.

Parrish FR. Allograft replacement of all or part of the end of a large bone following excision of a tumor: report of twenty-one cases. $J$ Bone Joint Surg [Am] 1973;55-A:1-22.

Paskert JP, Yaremchuk MJ, Randolph MA, Weiland AJ. The role of cyclosporin in prolonging survival in vascularized bone allografts. Flast Reconstr Surg 1987:80:240-7.

Sim FH, Chao EYS. Prosthetic replacement of the knee and large segment of the femur or tibia. J Bone Joint Surg [Am] 1979;61A $: 887-92$.

Sissons HA. Bones. In: Symmers WSC. Systemic Pathology 2nd ed. Vol. 5. Nervous system, muscle bone, joints. Edinburgh, etc: Churchil Livingstone, 1979:2384-8.

Urbaniak JR, Black KE Jr. Cadaveric elbow allografts: a six-year experience. Clin Orthop 1985:197:131-40. 